\title{
An alternative measure of structural unemployment*
}

\author{
Uluc Aysun ${ }^{\mathrm{a}^{* *}}$ \\ Florence Bouvet ${ }^{\mathrm{b}}$
}

Richard Hofler ${ }^{\mathrm{a}}$

${ }^{\text {a }}$ University of Central Florida,Orlando, FL32816

bonoma State University,Rohnert Park, CA 94928

June, 2012

\begin{abstract}
In this paper we derive an alternative measure for structural unemployment using a stochastic frontier analysis. This measure, by empirical design, is always less than total unemployment and it is, thus, more consistent with the theoretical description of structural unemployment than its usual interpretation as a smoothed long-run average of total unemployment. We find that our measure does not always track the long-run trends in total unemployment in the U.S. and when compared to the existing measures can produce different insights about the evolution of structural unemployment. Demographic and regional evidence provides some validation for our approach and allows us to determine how demographic and regional factors are related to the variation in structural unemployment across time and regions.
\end{abstract}

JEL Classification: E24; J21; J64; C13

Keyword(s): frictional, cyclical, structural unemployment, stochastic frontier.

* We thank the participants of the North American Productivity Workshop, VII and the University of Central Florida seminar series for helpful comments and discussions. We thank Robert Valetta for data help.

** Corresponding author: University of Central Florida College of Business Administration, 4000 Central Florida Blvd., P.O.Box 161400, Orlando, FL 32816. Email: Tel: (+1) 


\section{Introduction}

According to the standard definition, structural unemployment is the form of unemployment that results from a mismatch between the characteristics of the unemployed workers and those of jobs available, notably in terms of skills, work experience and geographical location (Jackman and Roper, 1987). Structural unemployment is only one component of the natural rate of unemployment that is defined by classical theory. The natural rate of unemployment also includes frictional unemployment -- short-run unemployment due to the frictions in the job search process. The other main form of unemployment, cyclical unemployment in contrast, results from workers losing jobs due to economic downturns.

Although labor theory that categorizes unemployment into its structural, frictional and cyclical forms is well-established, it is empirically difficult to separate structural unemployment from the other two main types of unemployment. In practice, structural unemployment is often used interchangeably with the natural rate of unemployment and measured by using univariate methods such as passing total unemployment through smoothing filters, and/or by the nonaccelerating inflation rate of unemployment (NAIRU) which is the rate at which the economy is neither expanding nor contracting (cyclical unemployment is zero). ${ }^{1}$ By construction, these measures of the natural rate of unemployment represent a long-run average measure of total unemployment. Consequently, total unemployment is sometimes lower than structural unemployment. $^{2}$

\footnotetext{
${ }^{1}$ The practice of using NAIRU to measure structural unemployment has not been without its critics. Salemi (1999) and Grant (2002), for example, argue that the natural rate of unemployment reflects microeconomic features of the labor market, whereas the NAIRU is predominantly an empirical macroeconomic relationship. Galbraith (1997) similarly argues that measuring the natural rate of unemployment with NAIRU implies that inflation stems from labor-market pressures, which might have led policymakers to tolerate needlessly high unemployment rates.

${ }^{2}$ If the natural rate of unemployment is instead represented by the sum of frictional and structural unemployment then using NAIRU implies that total unemployment can be less than frictional plus structural unemployment.
} 
This behavior of the unemployment measures is hard to justify since structural unemployment, by definition, is only a component of total unemployment and should always be smaller. In this paper, we construct an alternative measure of structural unemployment that is consistent with its standard definition. In doing so, we use a stochastic frontier analysis and assume that structural unemployment, the stochastic frontier, represents the minimum attainable point for total unemployment (net of frictional unemployment) and thus it is always smaller. Of course, structurally unemployed workers can find jobs and/or workers categorized under cyclically unemployed can become structurally unemployed during the business cycle. Our methodology, however, implicitly assumes that the total number of structurally unemployed workers is always smaller than the total number of unemployed. In other words, if a worker is structurally unemployed, on average, this worker will not find a job even if the economy is expanding. This is consistent with the theoretical description of structural unemployment. Specifically, if a worker for example lacks the skills to find a job, an expanding economy does not directly provide him with the necessary skills. We should note, however, that our measure of structural unemployment is not fully insulated from business cycles and that it can account for the stylized fact that during long lasting economic downturns (expansions), structural unemployment can increase (decrease). ${ }^{3}$

Stochastic frontier models originally designed by Aigner, Lovell, and Schmidt (1977) and Meeusen and van den Broeck (1977) to allow for and identify technical efficiency in the production process (such as that described by a Cobb-Douglas production function) have been more commonly used to study microeconomic topics. Focusing on a macroeconomic topic, we make a first attempt in this paper at applying a stochastic frontier methodology to identify

\footnotetext{
${ }^{3}$ This behavior of our measure is consistent with the hysteresis and duration hypothesis (Røed, 1997; Blanchard and Summers, 1987).
} 
structural unemployment. In doing so, we follow two steps. We first extract the frictional rate of unemployment from total unemployment using the trade frictions model of Lipsey (1960). We then use an expectations-augmented Phillips curve to extract cyclical unemployment and generate a time-varying measure of structural unemployment. Our methodology deviates from a standard stochastic frontier analysis in two ways. First, while a large majority of the studies in the literature model the frontier as the maximum attainable point we measure it as the minimum point that total unemployment (net of frictional unemployment) can attain. Second, we assume that structural unemployment has persistence and follows an AR(1) process. This assumption generates a composite error term that is more complicated than the usual composite error term in stochastic frontier modeling. We follow a stochastic cost frontier modeling strategy and prove that our error term is similar to the usual error term and obtain our measure of structural unemployment.

Our methodology has several advantages over more commonly used methodologies and our measure, compared to existing measures, at times illustrates different long-term trends in structural unemployment. A comparison with the time-invariant measures of structural unemployment shows that our measure is always smaller as expected (e.g. Rissman, 1986). Our measure, however, has the advantage of illustrating the secular trends in structural unemployment possibly generated by hysteresis or the duration of economic downturns (expansions). Comparing with the time-varying measures obtained by using Hodrick-Prescott (HP) filters and Kalman filter estimations of NAIRU (as in Richardson et al., 2000; Staiger et al., 1997; Turner et al., 2001), we find conflicting results. ${ }^{4}$ For example, Congressional Budget Office's (CBO) Kalman filter based NAIRU measure indicates a decline in structural

\footnotetext{
${ }^{4}$ We should also note that, although very few, there have been previous attempts at measuring structural unemployment using a Beveridge curve analysis. Jackman and Roper (1997) and Osberg and Lin (2000) for use this analysis to measure the structural unemployment rates in the United Kingdom and Canada, respectively.
} 
unemployment going from 1970s to 1980s, whereas our measure indicates an increase. Our methodology offers a distinct advantage over the CBO measure. The time variation in the CBO's measure of structural unemployment is generated by the participation rates of different demographic groups. The structural unemployment rates within each group are constant throughout the sample period and thus the time variation of these rates is not considered. By contrast, our measure represents both the participation rates of different demographic groups and the time variation within each group. In a more rigorous analysis, we show that this disparity between our measure and the CBOs measure can produce conflicting results. For example, when we hold structural unemployment in each group constant (as in the CBO methodology), we find that structural unemployment has decreased during the Great Recession. When we do not make this restriction (as in our baseline methodology), we find that it has increased. ${ }^{5}$

More generally, we find that although our measure is positively correlated with total unemployment, it does not always represent the long-run trends in total unemployment unlike the other time-variant measures of NAIRU. ${ }^{6}$ For example, we find that the negative trend in total unemployment after 2001 was not due to a decrease in structural unemployment although the decline in total unemployment during the 1990s was accompanied by a decrease in structural unemployment. Therefore, our measure demonstrates conflicting trends when compared to the other measures of structural unemployment and does not represent a smoothed series of total unemployment.

\footnotetext{
${ }^{5}$ This is no surprise given that the labor force participation rates of demographic groups with high levels of structural unemployment throughout the whole sample period has decreased during the Great Recession.

${ }^{6}$ Of course, long lasting economic expansions (downturns) can accelerate (decelerate) skill acquisition but in general measuring structural unemployment as NAIRU or as a long run moving average of total unemployment can be misleading because the estimates might vary even when there is no change in the true natural rate of unemployment (see, Thirlwall1983). Estimates might exhibit a cyclical pattern, as short-term variations in NAIRU are more likely due to cyclical variation in demand rather than to changes in the labor market structures. This would tend to an overestimation of the natural rate of unemployment during economic downturns.
} 
In the second half of the paper we proceed by checking the soundness of our analysis by investigating demographic and regional evidence. Consistent with the literature, we find that structural unemployment rates are higher for workers between ages 16 and 19 and for nonwhite workers. Our results, however, do not indicate a gender gap in structural unemployment. ${ }^{7}$ In our regional analysis we investigate, controlling for demographic characteristics, the industrial structure of U.S. census regions as possible determinants of structural unemployment. Our panel model estimations show that primary (high-productivity) industry and secondary (lowproductivity) industry shares, as expected, are negatively and positively related to structural unemployment, respectively. We find that these relationships are economically important. Specifically, if a region reallocates 1 percent of its production from its primary industry to its secondary industry, its structural unemployment increases by 0.2 percent.

The rest of the paper is organized as follows: in Section 2 we describe the model and the data that we use to identify frictional unemployment. In Section 3, we discuss our stochastic frontier methodology and describe how we obtain our measure of structural employment. In Section 4, we present our demographic and regional findings. Section 5 concludes.

\section{Disentangling the frictional component of unemployment}

To obtain the structural component of unemployment, we begin by generating a measure of unemployment that is net of frictional unemployment. In the next section, we will then separate this measure of net unemployment into its cyclical and structural components. In this section, we identify frictional unemployment using the trade frictions model of Lipsey (1960).

In the model economy there are two types of workers, unemployed workers that search for jobs and apply to vacant positions and workers whose jobs have recently been terminated or

\footnotetext{
${ }^{7}$ We discuss the theoretical reasons for this finding later in the paper.
} 
have recently quit. Let $V_{t}, J_{t}, E_{t}, U_{t}$ and $L_{t}$ denote the number of job vacancies, the number of jobs, and the number of employed, the number of unemployed and the labor force, respectively, then the number of vacancies and unemployed workers are defined by,

$V_{t}=J_{t}-E_{t}$

$U_{t}=L_{t}-E_{t}$

In this economy, employment does not grow by the difference in the vacancy rate and the rate of layoffs/quitting since there are frictions in the job search process. The number of searching workers who find jobs, $F_{t}$, is determined by the following constant returns to scale matching function,

$F_{t}=\beta\left(U_{t} V_{t}\right)^{1 / 2}$

where parameter $\beta$ (hereafter, the entry rate) governs the rate at which workers find jobs. Therefore, the evolution of employment in this economy depends on the number of newlyemployed and layoffs/separations.

$E_{t+1}=E_{t}+\beta\left(U_{t} V_{t}\right)^{1 / 2}-\gamma E_{t}$

where $\gamma$ is the rate (hereafter, the separation rate) at which workers lose/quit their jobs.

As in Warren (1991), we extend this standard Lipsey (1960) framework by assuming that the actual number of entries, $F^{a}$ (normalized by the number of employed), is subject to measurement errors, random shocks and technical inefficiencies.

$F_{t}^{a}=\beta_{t}\left(\frac{U_{t} V_{t}}{E_{t}^{2}}\right)^{1 / 2}+\omega_{t}-\mu_{t}$ 
Where $\omega_{t}$ is a random variable that represents measurements errors and random shocks and $\mu_{t}$ is a random variable that represents the technical inefficiencies in the job-matching process.

The steady state of this model corresponds to an economy in which employment is not growing and thus cyclical and structural factors do not affect employment. The frictional rate of unemployment, denoted by $u_{t}^{f}$, in this steady state can be derived by combining equations (4) and (5) (and replacing $F_{t}$ with $F_{t}^{a}$ ) as follows.

$u_{t}^{f}=\frac{\left(\gamma+\mu_{t}-\omega_{t}\right)^{2} E_{t}^{2}}{\beta V_{t}}$

To empirically derive this frictional unemployment variable we estimate the following employment evolution equation,

$$
\frac{E_{t+1}-E_{t}}{E_{t}}=\lambda_{0}+\lambda_{1}\left(\frac{U_{t} V_{t}}{E_{t}^{2}}\right)^{1 / 2}+\lambda_{2} T+\omega_{t}-\mu_{t}
$$

where the time trend $T$ is included to account for employment growth and $\lambda_{0}=-\gamma, \lambda_{1}=\beta$, $\lambda_{2}=-\gamma_{1}$.

\section{Data and the estimation strategy}

To estimate equation (7) one needs unemployment, employment and vacancy data. We obtain monthly, total unemployment and employment data from the Bureau of Labor Statistics (BLS), Current Population Survey for the 1960:1-2010:9 period. Obtaining historical vacancy data, however, is not as straightforward. BLS has only recently (since December 2000) made these data available (through its Job Openings and Labor Turnover Survey (JOLTS)). Prior to 2000, researchers mostly use the Conference Board's help-wanted index as an indicator of the 
vacancy rates. In our analysis, we extend the JOLTS vacancy rate data historically using the help-wanted index. This allows us to generate monthly vacancy rates from 1960:1 to 2010:9. The sample period is thus determined by the availability of the vacancy rates. Since the vacancy rate data are not seasonally adjusted, the unemployment and employment data are not seasonally adjusted in this section. ${ }^{8}$

In estimating the stochastic frontier model in equation (7), we follow the standard practice and assume that $\omega_{t}$ and $\mu_{t}$ are normally and half-normally distributed, respectively. Since our focus in this paper is structural unemployment, we defer the estimation results to Appendix A. We should, however, note that throughout the sample period, the frictional rate of unemployment is approximately 3 percent and that this rate is higher in the 1990s and 2000s compared to the earlier decades. Although scarce, other estimates of the average rate of frictional unemployment in the U.S. (also reported in Appendix A) are slightly higher than our measure. This disparity may be due to the differences in the unemployment data and sample periods. For example, Warren (1991) and Lilien (1980) use manufacturing unemployment and we use total unemployment data, and Michaillat (2012) uses data from 2000-2009, although the simulations are conducted for the period 1964-2009. There are various determinants of frictional unemployment that can also explain why we find that it has risen in the past two decades such as advances information technology, government sponsored training and re-training programs and slacks in the labor market. Our results support the negative relationship between slacks in the labor market and the level of frictional unemployment suggested by theory (see, Michaillat, 2011). According to this theory, the relative boom that the U.S. economy has experienced in the

\footnotetext{
${ }^{8}$ Since we focus on the long-term trends in total, structural unemployment, we do not make seasonal adjustments throughout the paper.
} 
past two decades, despite the recent recession, may have increased the difficulty and the costs of recruitment.

In the rest of the paper, we use the level of total unemployment that is net of the frictional unemployment. For simplicity, we refer to this net level of unemployment as unemployment.

\section{Identifying the structural component of unemployment}

In this section, we proceed by decomposing the unemployment variable, measured in the previous section, into its cyclical and structural components. To do so, we estimate the following expectations-augmented Phillips curve (with backward-looking expectations).

$$
\Delta \pi_{t}=\alpha(L) \Delta \pi_{t-1}+\beta(L)\left(u_{t}-u_{t}^{*}\right)+\delta(L) z_{t}+\varepsilon_{t}
$$

where $\pi_{t}, u_{t}, z_{t}$ are the inflation rate, the unemployment rate and a vector of supply side shocks, respectively. $L$ is the lag operator and $\varepsilon_{t}$ is the standard serially uncorrelated, normally distributed error term. In equation (10) $u_{t}^{*}$ denotes our measure of structural unemployment. Compared to the standard practice that interprets $u_{t}^{*}$ as NAIRU, the key difference in this paper is that we assume $u_{t}^{*}$ cannot be greater than $u_{t}$. More specifically, let $v_{t}$ denote the difference between total unemployment, net of frictional unemployment, and structural unemployment,

$v_{t}=u_{t}-u_{t}^{*}$

we assume that $v_{t}$ is always greater than zero and half-normally distributed. We assume further that the structural unemployment obeys the following first-order auto-correlation process:

$u_{t}^{*}=\rho u_{t-1}^{*}+\omega_{t}$

where the $\omega_{t}$ is a half-normally distributed error term and $\rho$ denotes the persistence parameter. 
Notice that we cannot estimate equation (8) since $u_{t}^{*}$ is not observable. To obtain a form of equation (8) that we can estimate and thus recover our measure of structural unemployment, we substitute equation and (10) into equation (8) and use algebraic manipulations. These straightforward steps produce the following:

$$
\Delta \pi_{t}=\alpha(L) \Delta \pi_{t-1}+\delta(L) z_{t}+\beta(0) u_{t}-\beta(0) \rho u_{t-1}+\beta(0) w_{t}+\beta(0) \rho v_{t-1}+\sum_{n=1}^{k} \beta(n) v_{t-n}+\varepsilon_{t}
$$

The estimation of equation (11), however, is not straightforward. Although the composite error term in equation (11), similar to that in a standard stochastic frontier model, is a combination of a half-normally and normally distributed variables, it includes $k+1$ half-normally distributed variables (the standard stochastic frontier model has only one). The standard $p d f$ function describing the sum of a half-normal and a normal variable derived by Aigner et al. (1977), therefore, may not necessarily describe the error term in equation (11). In Appendix B we do however show that the sum of a linear combination of independent half-normal variables is also half-normal and in Appendix $\mathrm{C}$ we derive the $p d f$ function for the composite error term in equation (11). This critical proof and the derivation thus allow us to use the standard stochastic frontier model estimation methodology. In estimating equation (11) we impose the constraint that the sum of the inflation coefficients to equal 1 . This constraint is supported by data but more important allows us to avoid a long-run tradeoff between inflation and unemployment. It is wellestablished that this is tradeoff does not exist.

After estimating the model, we recover the structural unemployment rate using equation (8) as follows:

$u_{t}^{*}=\left(-\Delta \hat{\pi}_{t}+\hat{\alpha}(L) \Delta \pi_{t-1}+\hat{\beta}(0) u_{t}+\hat{\delta}(L) z_{t}\right) / \hat{\beta}(0)$ 
We should note at this point that in estimating equation (11) we are assuming that the frontier (the latent variable) is always less than the observed variable. This is different from the original application of stochastic frontier models in Aigner et al. (1977) and Meeusen and van den Broeck (1977). The authors simultaneously introduced stochastic frontier models to investigate the production process by allowing for technical inefficiencies in production (in addition to independently distributed random shocks). The inefficiency term in these studies are always negative and thus the observed production is also less than the frontier. In our model we assume that the technical inefficiency term is always positive and thus the observed unemployment is always greater than the frontier, i.e., our measure of structural unemployment. We are not the first to make this assumption. Studies such as Sav (2012), Duncan et al. (2012), Revoredo-Gilha et al. (2009), and Ludwig et al. (2009), when investigating microeconomic efficiency, assume that the frontier cost (minimum possible cost) is never greater than observed cost. In our estimations we follow this approach, more commonly known as stochastic cost frontier modeling.

\section{Data and baseline results}

To estimate equation (12) we obtain monthly unemployment data from BLS. The data are from the current population survey and span the period 1960:1 to 2010:9. To account for supply shocks we include the real growth rates of energy and import prices in the vector $z_{t}$. In measuring these growth rates we use the Consumer Price Index (CPI) for energy (for all urban consumers) and the price index for all imports excluding petroleum from the Federal Reserve Bank of St. Louis FRED database. We deflate both indices by using the CPI index excluding food and energy prices (index used to measure core inflation) to obtain real growth rates. One drawback to using import prices is that it is available only after 1989:1. When estimating 
equation (12) we thus use two sample periods, 1960:1-2010:9 and 1989:1-2010:9. The former dataset does not include the import price index but covers a longer time period. This is advantageous because it allows us to compare our measure of structural unemployment with demographic and regional trends over a broader time period. We use the CPI index excluding food and energy prices to also construct the dependent variable in equation (11), i.e, inflation. We include 12 lags of the inflation and energy price growth variables on the right hand side. When using the 1989:1-2010:9 period, we include three lags of the import price growth variable. ${ }^{9}$ Finally, when we use the 1960:1-2010:9 sample period, we account for the wage and price controls in 1971 and the removal of these controls in 1974 by including dummy variables on the right hand side of equation (11). ${ }^{10}$

We graph the structural unemployment variable calculated from the estimation of equation (12) in Figures 1 and 2 (the estimation results for both sample periods are reported in Table A.2 of Appendix A). A comparison of the evolution of total and structural unemployment in Figure 1 suggests that, although total and structural unemployment are positively related, the correlation is less than perfect. For example, while total unemployment noticeably decreases after the recession in 2001, structural unemployment remains relatively stable. In the second half of the 1990s, in contrast, cyclical and frictional unemployment remains stable and the decrease in total unemployment is mainly due to the decrease in structural unemployment. Our measure displayed in Figure 2 reveals two trends in structural unemployment prior to 1989: a positive trend from early 1970s to mid-1980s, followed by a negative trend until the recent crisis.

\footnotetext{
${ }^{9}$ A majority of the studies in the literature use quarterly data and the number of lags of the right hand side variables in these studies range from 1 - 8 (usually the number of lags for the inflation variable are higher). This corresponds to 3 to 24 lags in our monthly sample. We choose to use 3 lags of the import price variable since its availability is limited. However we obtained similar results when we used a larger number of lags.

${ }^{10}$ The first and second dummy variables equal 1 from 1971:9 to 1972:9 and 1973:9 to 1974:12, respectively.
} 
In Table 1 we summarize the results in Figure 2 and compare our measure with the other measures of structural unemployment. In every comparison, we find that our measure of structural unemployment is lower. This is not an unexpected result given that, by design, our measure represents the lower bound for unemployment. This disparity, of course, would not justify our analysis by itself if the evolution of our measure over time closely mimicked the other measures and the only difference was that our measure had a smaller mean. When we compare the evolution of our structural unemployment measure with the other measures, we do however find conflicting results. For example, our measure indicates an increase in structural unemployment going from the 1970s to the 1980s. Conversely, the CBO's NAIRU measure declines over the same period. Compared to the CBO measure we also find a much more pronounced increase in structural unemployment in the 1970s and the recent crisis.

Notice that we are comparing the mean value of our measure across broad periods of time instead of computing simple correlations. We do this mainly because the CBO measure is much smoother than our measure and thus simple correlations are low. At this point we should highlight a key difference between our methodology and that of $\mathrm{CBO}$ and other studies that follow the same approach. The time-variation in the $\mathrm{CBO}$ measure reflects the changes in the labor force participation rates of different demographic groups (age, gender and race). To obtain their measure $\mathrm{CBO}$ assumes that the structural unemployment of the different demographic groups is constant over time. ${ }^{11}$ In obtaining our measure, we do not impose this restriction. Our measure, therefore, not only captures the changes in the labor force participation rates but also

\footnotetext{
${ }^{11}$ CBO uses the unemployment rate of a reference group, married males, to measure the level of demand in the economy. CBO then obtains an estimate of the NAIRU for the married male workers groups by estimating the Philips curve equation for that demographic group. To estimate the NAIRU of other demographic groups, the CBO first regresses the unemployment rate of these demographic groups on the unemployment rate of married males. Then the overall NAIRU is computed as a weighted average of each group's NAIRU, where shares in the labor force are used as weights. Since each demographic group's NAIRU is assumed constant throughout the period, the overall NAIRU varies over time only because the shares in labor force are changing over time.
} 
the factors that impact structural unemployment within demographic groups such as sectorspecific and technological trends.

Comparing our results with those obtained from other time-variant measures of structural unemployment such as in Turner et al. (2001) and Grant (2002), we also find conflicting results. For example, Turner et al. (2001) find that structural unemployment has decreased from 1980 to 1985. We find that it has slightly increased over this period. Similarly, Grant (2002) find a decrease in structural unemployment going from the 1960s to the 1970s. We find that structural unemployment has more than doubled during the same period. Both of these measures are obtained by using a filter (Kalman filter in Turner et al., 2001 and Hodrick-Prescott filter in Grant, 2002) and, similar to the CBO measure, are smoother than ours since these filtering techniques allow one to specify the smoothness of the filtered series. Although it is straightforward to apply this procedure to our structural unemployment measure we prefer to compare our results over a broader period of time to make a comparison. We do this mainly because we define structural unemployment as a more dynamic variable that, as explained above, not only reflects changes in the demographic composition of the labor force but also reflects economic trends. We investigate demographic data in the next section to more clearly identify this unique feature of our measure.

We cannot compare our measure across different decades for a majority of the studies in the literature mainly because most of these studies estimate a single, long run value of structural unemployment. We do however find, as displayed in Table 1, that our measure is always smaller.

\section{Demographic and regional evidence}

In this section we follow the procedures above to compute the structural unemployment rates for different demographic groups and different regions in the U.S. and identify the trends in 
the structural unemployment of these groups and regions. We also study the regional characteristics of structural unemployment and determine how our measure is related to the labor force participation rate of different demographic groups.

\section{Demographic evidence}

To investigate demographic evidence we obtain gender, age, and race-specific unemployment data from the Bureau of labor statistics. These different groups, also used by the CBO, are listed in Table 2. Although it is possible to divide the labor force into narrower categories and/or into different demographic groups, we choose to use this classification since we compare our results to those obtained by using the CBO classification.

The results are reported in Table 2. One important result is that the labor force participation rate is often negatively related to the structural unemployment rate. This demonstrates a key contradiction with other measures that estimate a single value for each demographic group and generate variation across time using the labor force participation rate. If a demographic group is participating more in the labor market and at the same time if its structural unemployment rate is decreasing (this is observed for the groups that have negative correlations in Table 2), then their contribution to the overall structural unemployment may not be positive as the other measures would predict. If the correlations are positive (as they are for age groups 20-24, 25-34 and 65+), this would then imply that using only LFPR to generate time variation would understate the contribution of different demographic groups to the overall variation in structural unemployment.

To more rigorously check whether different inferences can be drawn when structural unemployment is assumed to be constant throughout the sample period, we conduct the following exercise. We begin by estimating equation (11), assuming that the structural 
unemployment rate is constant. We do this for each demographic group (male, female, white, nonwhite, ages 16-19, 20-24, 25-34, 35-44, 45-54, 55-65, 65+). We then multiply these constant rates of structural unemployment by the labor force of each group. This gives us the number of structurally unemployed workers in each group. Finally, we aggregate these unemployed workers by gender, race and age and divide the sum by the labor force to obtain the static measure of structural unemployment. It is important to note that although we refer to this measure as static structural unemployment, it varies across time. Notice that the static feature of this measure is the assumption of constant structural unemployment in its calculation. Thus the variation across time only reflects the changes in the proportion of the different groups in the labor force and not the changes in each group's structural unemployment. In measuring the dynamic structural unemployment variable, by contrast, we allow structural unemployment in each subgroup under gender, race and age to vary across time. After measuring this variable for each subgroup, we obtain the total percentage of structural unemployment by aggregating across age, gender and race. We use the monthly labor force variable for each subgroup (for example male and female for gender) to find the aggregate structural unemployment rate.

The results displayed in the bottom panel of Table 2 reveal conflicting results. In other words, when the structural unemployment of different demographic groups is allowed to change the results obtained can be different than the results obtained by restricting the structural unemployment rates to be constant over time. For example, while the dynamic measure demonstrates an increase in the 1980s compared to the 1970s, the static measure shows a decline or no change. Similarly, during the recent crisis while the static measure indicates a decrease in structural unemployment, the dynamic measure indicates an increase. The former observation is consistent with the considerable decline in the labor force participation rate for the 16-19 ages 
subgroup (and to a lesser extent for the non-white subgroup). But notice that while the participation rate has declined during the crisis, the structural unemployment has increased for this group. The similar negative correlation observed across different groups explains the conflicting results that we find at the bottom panel of Table 2.

\section{Regional evidence}

In this section, we first measure the structural unemployment rate for the 9 US census regions using our baseline methodology. We then investigate how these measures are related to region-specific characteristics. To generate the structural unemployment variables we obtain monthly regional unemployment and labor force data from the BLS that spans the period 1976:12010:12. As in Section 3, we use the HWI at the regional level to obtain the vacancy rate data for our sample period, and we use the same measures for inflation and the same control variables in equation (8).

Table 3 displays the average rates of structural unemployment for the regions that we generated along with some region specific characteristics. In general, we observe a decline in structural unemployment since to 1980s until the recent crisis and an increase thereafter. There are, however, exceptions and the magnitudes of the changes across time are different. For example, the West South region's structural unemployment has decreased during the recent crisis and while the New England region's structural unemployment rate has changed by only a small amount from the 1980s to the 1990s, there is a sharp drop in the East North Central region's structural unemployment rate.

In a second stage panel regression (discussed below), we try determine how these different experiences of the regions are related to the variables that are reported in the bottom half of Table 3. We consider industrial decomposition in the regions since there is a broad, long- 
standing literature that identifies the differences in the averages wage and skill requirements across industries as the main determinants for long-term structural unemployment (e.g. Bulow and Summers, 1986; Dickens and Weiler (1993); Neumann and Topel, 1991; Phelps, 1970; Summers, 1986). Thus, differences in structural unemployment across regions are possibly caused by the industrial decomposition of regional production.

Although there are different industrial classifications, according to the well-known three sector hypothesis of Clark (1940), the evolution of economic structure can be captured by considering the production share of three industries. The main activity in the primary sector industries is the extraction of raw materials and natural resources. The secondary sector uses these raw materials in the manufacturing and constructions processes and the tertiary sector is represented by service activities. While the primary sector in the US is characterized by high skill requirements, labor productivity and wages, the secondary and tertiary sectors have low skill requirements, productivity and wages (Kendrick and Grossman, 1980; Jorgenson et al., 1987; Jorgenson et al., 2005; Ball et al., 2010). This is important for regional differences in structural unemployment since there is evidence showing that low-skilled workers may have larger rates of structural, long-term unemployment. ${ }^{12}$ Thus, if a region has a high share of services sector production then one would expect a high rate of structural unemployment in this region. However, this positive relationship is not observed for every subcategory of services. For example, Kirkegaard (2009) finds that while structural unemployment is higher (especially recently) in the financial services sector, it is lower in the healthcare, education, food, and professional/technical services sectors. There is also evidence indicating that hysteresis may not always be more effective in low-skill sectors (such as services). Rothstein (2012), for example,

\footnotetext{
${ }^{12}$ Oesch (2010) and Roed (1997) argue that hysteresis during extended periods of economic downturns can be more intensive for low-skilled workers.
} 
finds that during the recent crisis the decline in the employment rate in the finance and real estate sectors were not too different from the economy-wide averages and that the decrease in manufacturing and construction sectors were much higher.

Given these findings, below we investigate whether the differences in the industrial composition of regions (For example, Table 3 reports that while the primary sector share in the West South Central region is 12.3 percent, it is 0.7 percent in New England) is a determinant of the variation in their structural unemployment rates. Following the standard classification, we include the agriculture and mining sectors in the primary industry, manufacturing and construction sectors in the secondary industry and the service sectors in the tertiary industry. ${ }^{13}$

Turning to demographic variables, we consider the women's labor forced participation rate and share of population, percentage of white population, share of population between the ages of 15 and 64 and the overall labor force participation rate as possible determinants of structural unemployment. Although we could not find a study that investigates the presence gender gaps in structural unemployment, we found indirect evidence suggesting that the relationship between the share of women in the labor force and the structural unemployment rate may be negative or positive. On the one hand, studies such as Hoynes et al. (2012) and Kochhar (2011) find that women are less sensitive to the business cycle. During the Great Recession, for example, the decrease in the employment of men was much larger than for women (referred to as "man-cession" in the literature). A similar pattern was observed during the early 1980s recession. Thus if women tend to keep their jobs during sharp economic downturns, they may be less vulnerable to hysteresis and structural unemployment rate may be lower for women. On the other hand, there is evidence showing that, despite the large increases in their labor force participation

${ }^{13}$ The sectors classified under the tertiary industry are: retail trade, services, financial, real estate, insurance, transportation and public utilities, wholesale trade and government. 
rates, the duration of unemployment has increased for women since the 1960s. Studies such as Abraham and Shimer (2002) argue that this trend was caused by the increasing labor force attachment of women. According to this theory, since women have a stronger attachment to the labor force, they tend to stay unemployed when they lose their jobs, rather than dropping out of the labor force. This evidence augments the higher rates of structural unemployment observed among women when their labor force participation rates were increasing rapidly in the earlier parts of our sample period. Structural unemployment, therefore, can also be higher for women in the whole sample period.

There is less uncertainty in the literature that the structural unemployment rate among non-white population is higher (e.g. Johnson and Layard, 1986) and that the structural unemployment rate for workers 65 and over is considerably smaller. ${ }^{14}$ Finally, the variation in structural unemployment rate can be due to the high-skill and low-skill workers' entry into and exit out of the labor force (for example, the entry of low-skill baby boomers 1970s and 1980s and the retirement of high-skill baby boomers in the late 2000s). We thus consider the share of non-white population, the share of workers with ages between 16 and 65 and the labor force participation rate as potential determinants of structural unemployment across time and regions.

We use these demographic and industrial structure variables in the following panel model to investigate the regional determinants of structural unemployment.

$u_{i t}^{*}=B(L) u_{i t}^{*}+C(L)$ ind $_{i t}+D(L) \operatorname{dem}_{i t}+\varepsilon_{i t}$

\footnotetext{
${ }^{14}$ Kwok et al. (2010) argue that older workers do not remain in the labor force after they unemployed as much as they did before the 1950s since the increases in social security, pension, and retiree health benefits made early retirement more favorable (although this trend has recently reversed).
} 
where $i, t$ and $L$ are the region and time indices and the lag operator, respectively, $u_{i t}^{*}$ is the regional structural unemployment rate and ind ${ }_{i t}$ and $\operatorname{dem}_{i t}$ is a vector of the industrial structure and demographic variables described above.

In estimating equation (13) we use annual data from 1970 to 2010. Although the regional industry shares in production (GDP) are available annually from the Bureau of Economic Analysis, the regional demographic variables are only available through the U.S. Census records that are compiled every 10 years. ${ }^{15}$ Since our focus in this paper is the long-term trends in structural unemployment, we construct the dependent variable (and its lags) and the industry share variables as averages across 3 and 5 years. ${ }^{16}$ In doing so, we use the demographic variables at the beginning of the decade across which the industry shares and the dependent variables are measured. For example, demographic variables in 1990 are matched with averages of industry shares computed across the period 1991-1993 (and the other 3-year periods in the decade).

To estimate the panel model in equation (13) we use the system GMM methodology of Arellano and Bover (1995) and Blundell and Bond (1998). We follow this strategy because the estimator allows us to remove unobserved time-invariant region-specific effects, control for heteroskedasticity and autocorrelation within regions, account for the potential endogeneity of the right-hand side variables and to account for the nonstationarity of the dependent variable. We include 2 lags of the dependent variable and 3 lags of the industry share variable on the right hand side and we use 4 to 6 period lags of the dependent variable and the primary and secondary industry shares as instruments.

\footnotetext{
${ }^{15}$ We obtain state-level data for annual share of industries in the gross domestic product. We then aggregate these data to obtain regional shares.

${ }^{16}$ We considered the frequencies of 1,2 and 4 years and obtained similar results. Using more than 5 years to take averages, however, reduced our sample size considerable and most of the coefficients were insignificant.
} 
The results obtained by using 3 and 5 year averages of the industry shares are displayed in Table $4 .{ }^{17}$ The numbers reported for the industry shares and the structural unemployment represent the summation over the lagged variables' coefficients (3 lags). As expected, we find that the share of the primary (high-productivity) and secondary (low-productivity) sectors' production is negatively and positively related to structural unemployment, respectively. These relationships are significant both when we include and exclude demographic variables. We do, however, find that the tertiary sector production is negatively related to structural unemployment. Thus the lower levels of structural unemployment in some of the sub-categories of the tertiary sector and the smaller degrees of hysteresis associated with low-skill sectors (more recently observed) may be the more important determining factors of structural unemployment. The magnitudes of the industry share coefficients also indicate that they are economically meaningful. The values -0.143 and 0.062 reported in the first column, for example, suggest that if a region reallocates 1 percent of its production from its primary industry to its secondary industry, its structural unemployment increases by 0.2 percent.

Out of all the demographic variables, we find that the labor force participation rate of women and whole adult population are the only ones that are consistently significant. We find that while the labor force participation rate of women is positively related to structural unemployment, the labor force participation rate of the adult population is negatively related. These results thus imply that structural unemployment is larger for women than for men and they support the labor attachment/duration hypothesis discussed above. Although insignificant, we also find (as expected) that the share of white population in the labor force is negatively related to structural unemployment. Table 4 shows that the results are similar when we use 5-year

\footnotetext{
${ }^{17}$ The numbers in parentheses for the industry share and structural unemployment lags are the F-statistics that indicate whether the sum of the industry share and structural unemployment coefficients (3 lags) are significantly different from zero. The rest of the values in the parenthesis are the coefficient standard errors.
} 
averages. Although, we should note that the demographic variable coefficients are not as significant possibly due to the smaller sample size. In each estimation, Sargan test for overidentifying restrictions suggested that the instruments were valid and we could not find any evidence for second order serial correlation in the error term.

\section{Concluding remarks}

In this paper we derived an alternative measure for structural unemployment. This measure by empirical design is always less than total unemployment and thus it is consistent with the usual theoretical description of structural unemployment. We also found that our measure, unlike existing measures, did not always represent long-run trends in total unemployment and behaved differently at times. Demographic and regional evidence provided some validation for our approach and also allowed so to gain more insight into how various demographic and regional factors affect structural unemployment.

Besides the useful information on the secular trends in labor markets, the accuracy in measuring structural unemployment can have important policy implications. Specifically, the potential efficacy of policies designed to reduce unemployment depends critically on the extent to which unemployment is due to frictional, cyclical or structural unemployment. "If policymakers are not able to distinguish higher unemployment rates due to a change in the structure of employment from higher unemployment rates due to a weak economy, then they run the risk of implementing expansionary policies at the wrong time, thereby creating or adding inflationary pressures” (Rissman, 1986, pp3). Accurately estimating structural unemployment thus improves monetary and fiscal policy formulation. While an accurate estimation of structural unemployment and NAIRU would help monetary policymakers assess inflationary developments in the short run (Ball and Mankiw, 2002), it would also help to measure the output gap and thus 
design the appropriate fiscal policy necessary to close that gap (Richardson et al., 2000). Thus, it would be a natural next step to investigate whether interpreting structural unemployment as a stochastic frontier in policy rules would improve policy formulation and bring more stability. Since our results showed that the structural unemployment rate increased considerably during the Great Recession (2007-2009), for example, it would be interesting to observe whether the effectiveness of the expansionary fiscal and monetary policies implemented in the United States and in Europe is limited by the more structural nature of unemployment. ${ }^{18}$

\section{References}

Abraham, K. and Shimer R. (2002) "Changes in Unemployment Duration and Labor Force Attachment.” In The Roaring Nineties, edited by Alan Krueger and Robert Solow. New York: Russell Sage Foundation.

Aigner, D., C.A.K. Lovell, and P. Schmidt. "Formulation and Estimation of Stochastic Frontier Production Function Models", Journal of Econometrics, 1977, 5, 2137.

Arellano, M. and O. Bover. (1995) "Another look at instrumental variables estimation of errorcomponent models.” Journal of Econometrics, 68, 29-51.

Arnold, R., (2008), "Reestimating the Phillips Curve and the NAIRU", Congress Budget Office Working Papers Series, , 2008-06.

Ball, V. E., Butault, J.P. San Juan Mesonada, C., Mora, R. (2010) "Productivity and International Competitiveness of European Union and United States Agriculture, 1973-2002," Agricultural Economics, 611-627.

Ball, L., Mankiw, N.G. (2002) "The NAIRU in theory and practice", Journal of Economic Perspectives, 16(4), 115-136.

Blanchard, O.J. and Summers L. H. (1987), "Hysteresis in unemployment”, European Economic Review, 31(1/2), 288-295.

Blundell, R., and S. Bond. (1998) "Initial conditions and moment restrictions in dynamic paneldata models.” Journal of Econometrics, 87, 115-143.

Bulow, J. and L.H. Summers. (1986) "A Theory of Dual Labor Markets with Application to Industrial Policy, Discrimination, and Keynesian Unemployment." Journal of Labor Economics, 4(3), 376-414.

Clark C. (1940) "Conditions of Economic Progress.” Macmillan, London.

Daly M., Hobijn B., Valletta R., (2011), "The recent evolution of the natural rate of unemployment”, Federal Reserve Bank of San Francisco, Working Paper 2011-05.

Dickens W.T. and Weiler S. (1993) "A Regional Dual Labor Market Model: The Case for Two Non-Market-Clearing Sectors.” Mimeo, University of California, Berkeley.

\footnotetext{
${ }^{18}$ This increase in structural unemployment is consistent with the inferences drawn from a Beveridge curve analysis (e.g. Weidner and Williams, 2011; and Daly et al., 2011).
} 
Duncan, K. C., P. Philips, and M. Prus. "Using Stochastic Frontier Regression to Estimate the Construction Cost Inefficiency of Prevailing Wage Laws,” Engineering, Construction and Architectural Management, 2012, 19, forthcoming.

Galbraith,J.K. (1997) “Time to ditch the NAIRU” Journal of Economic Perspectives, 11, 93-108.

Grant, A.P., (2002), "Tim-varying estimates of the natural rate of unemployment: A revisitation of Okun's Law”, The Quarterly Review of Economics and Finance, 42, 95-113.

Hoynes, H.W., Miller, D.L. and Schaller J. (2012) “Who Suffers During Recessions?” NBER Working Papers 17951.

Jackman, R. and Roper S. (1987). “Structural unemployment”, Oxford Bulletin of Economics and Statistics, 49(1), pp. 9-36.

Johnson, G.E. and Layard, R. (1986) "The natural rate of unemployment: explanation and policy.” Handbook of Labor Economics, North-Holland, Amsterdam, 1986.

Jorgenson, D., Gollop, F., Fraumeni, B. (1987) "Productivity and U.S. Economic Growth.” Cambridge MA: Harvard University Press.

Jorgenson, D., Ho, M., Stiroh. K. (2005) "Productivity: Information Technology and the American Growth Resurgence.” Cambridge: The MIT Press.

Kendrick, J.W., Grossman, E.S. (1980). "Productivity in the United States, Trends and Cycles." Baltimore MD: The Johns Hopkins University Press, 1980.

Kirkegaard J.F. (2009) "Structural and Cyclical Trends in Net Employment over US Business Cycles, 1949-2009: Implications for the Next Recovery and Beyond.” Working Paper Series WP09-5, Peterson Institute for International Economics.

Kochhar, R. (2011) "In Two Years of Economic Recovery, Women Lost Jobs, Men Found Them,” Pew Social \& Demographic Trends, Washington, D.C.

Kwok J., Daly, M. and Hobijn, B. (2010) "Labor Force Participation and the Future Path of Unemployment.” Federal Reserve Bank of San Francisco, Economics Letter, 2010-27.

Lilien, D. M. (1980) “The Cyclical Pattern of Temporary Layoffs in U.S. Manufacturing.” Review of Economics and Statistics, 62(1), 24-31.

Lipsey, R. (1960) "The Relation between Unemployment and the Rate of Change of Money Wage Rates in the United Kingdom, 1862-1957.: A Further Analysis." Economica 27, 1-31.

Ludwig, M., W. Groot, and F. Van Meroda. "Hospital Efficiency and Transactions Costs: a Stochastic Frontier Approach,” Social Science \& Medicine, 2009, 69, 61-67.

Meeusen, W. and J. van den Broeck (1977) "Efficiency estimation from Cobb-Douglas production functions with composed error.” International Economic Review, 1977, 8, 43544.

Michaillat P. (2012) “Do matching frictions explain unemployment?” American Economic Review, 102(4).

Neumann, G. R. and R.H. Topel. (1991) "Employment Risk, Diversification, and Unemployment." Quarterly Journal of Economics, 106(4), 1341-1365.

Oesch, D. (2010) "What explains high unemployment among low-skilled workers? Evidence from 21 OECD countries.” European Journal of Industrial Relations, 16(1), 39-55.

Osberg, L., Lin Z., (2000), “How much of Canada’s unemployment is structural?”, Canadian Public Policy, 26, S141-S-157.

Phelps, E. (1970) “Micro-Economic Foundations of Employment and Inflation Theory.” New York: Norton.

Revoredo-Giha, C., C. Milne, P. Leat, and W. Cho, "Efficiency of Scottish Farms; A Stochastic Cost Frontier Analysis,” Agricultural Economics Review, 2009, 10, 17-35. 
Richardson, P., Boone L., Giorno C. , Meacci M., Rae D. , and Turner D., (2000), “The Concept, Policy Use and Measurement of Structural Unemployment: Estimating a Time Varying NAIRU Across 21 OECD Countries", OECD Working Papers, 250.

Rissman, E.R. (1986), "What is the natural rate of unemployment?”, Federal Reserve Bank of Chicago Economic Perspectives, 10, September-October, 3-17.

Røed, K. (1997) "Hysteresis in unemployment”, Journal of Economic Surveys, 11(4), 389-418.

Rothstein J. (2012) "The Labor Market Four Years Into the Crisis: Assessing Structural Explanations.” NBER Working Papers 17966.

Salemi, M.K., (1999), "Estimating the natural rate of unemployment and testing the natural rate hypothesis", Journal of Applied Econometrics, 14, 1-25.

Sav, G. T. "For-Profit College Entry and Cost Efficiency: Stochastic Frontier Estimates vs. TwoYear Public and Non-Profit Colleges,” International Business Research, 2012, 5, 26 - 32.

Staiger, D., Stock J. H., and Watson M. W. (1997), "How precise are estimates of the natural rate of unemployment?” in Reducing inflation: Motivation and strategy, editors: C.D. Romer and D. H. Romer, Chicago Press.

Summers, L. (1986) "Why is the Unemployment Rate So Very High Near Full Employment?" Brookings Papers on Economic Activity, 2, 339-383.

Thirlwall, A.P., (1983), "What are the estimates of the natural rate of unemployment measuring?”, Oxford Bulletin of Economics and Statistics, 45(2), 173-179.

Turner D., Boone L., Giorno C., Meacci M., Rae D., and Richardson P., (2001), "Estimating the structural rate of unemployment for the OECD countries”, OECD Economic Studies No. 33, 2001/II

Weidner J., and Williams J. C., (2011), “What is the new normal unemployment rate?”, Federal Reserve Bank of San Francisco Economic Letter, \# 2011-05, February 14, 2011.

Walpole, R. E., R. H. Myers, S. L. Myers, and K. E. Ye (2011), Probability and Statistics for Engineers and Scientists, 9th edition, Pearson: New York.

Warren R.S. (1991) "The Estimation of Frictional Unemployment: A Stochastic Frontier Approach.” The Review of Economics and Statistics, 73(2), 373-377. 


\section{Appendix A. Stochastic Frontier model estimation results}

Table A.1 Frictional unemployment, estimation and average rates

\begin{tabular}{|c|c|c|c|c|c|c|}
\hline \multicolumn{7}{|c|}{ Estimation results: Equation (7) } \\
\hline \multirow[t]{2}{*}{$\lambda_{0}$} & 0.0096 & & & & & \\
\hline & $(0.0030)^{* * *}$ & & & & & \\
\hline \multirow[t]{2}{*}{$\lambda_{1}$} & 0.1281 & & & & & \\
\hline & $(0.0607)^{* *}$ & & & & & \\
\hline \multirow[t]{2}{*}{$\lambda_{2}$} & -0.113 & & & & & \\
\hline & $(0.0205)^{* * *}$ & & & & & \\
\hline Nobs & 609 & & & & & \\
\hline \multicolumn{7}{|c|}{ Average rate of frictional unemployment } \\
\hline & $1960 \mathrm{~s}$ & 1970 s & 1980s & 1990s & $2000-2010$ & Mean \\
\hline$u^{f}$ & 2.79 & 2.52 & 2.59 & 3.03 & 3.74 & 2.95 \\
\hline \multicolumn{2}{|c|}{ Other estimates } & & estimate & sample period & & \\
\hline & Lilien (1980) & & $3.5 \%$ & 1969-1973 & & \\
\hline & Warren (1991) & & $3.7 \%-4.8 \%$ & 1969-1973 & & \\
\hline & Hofler and $\mathrm{Ml}$ & ny (1989) & $5.2 \%$ & 1960-1979 & & \\
\hline & Michaillat (201 & & $3.9 \%$ & 1964-2009 & & \\
\hline
\end{tabular}

Note: The results are from the estimation of equation (7). ${ }^{* *}$ significant at $5 \%$; ${ }^{* * *}$ significant at $1 \%$.

Table A.2. Structural unemployment estimation

\begin{tabular}{|c|c|c|}
\hline & $1960-2010$ & $1989-2010$ \\
\hline$\beta$ & -0.065 & 0.057 \\
\hline$\rho$ & $(0.026)^{* *}$ & $(0.032)^{*}$ \\
\hline & 1.027 & 0.962 \\
\hline Inflation lags & $(0.061)^{* * *}$ & $(0.091)^{* * *}$ \\
\hline & 1.000 & 1.000 \\
\hline Energy prices & $(801.1)^{* * *}$ & $(523.7)^{* * *}$ \\
\hline & 0.266 & 0.128 \\
\hline import prices & $(9.461)^{* * *}$ & $(4.072)^{* *}$ \\
\hline & & 0.074 \\
\hline$d 1$ & 0.00018 & $(2.153)$ \\
\hline & $(0.00046)$ & \\
\hline & -0.003 & \\
\hline Nobs & $(0.001)^{* * *}$ & \\
\hline
\end{tabular}

Note: This table reports the results obtained from the estimation of equation (11). The numbers in parentheses for the inflation, energy prices and import prices are the F-statistics that test for joint significance. The price control dummy variables, $d 1$ and $d 2$ equal 1 from 1971:9 to $1972: 9$ and 1973:9 to $1974: 12$, respectively. ${ }^{*}$ significant at $10 \%$; ** significant at $5 \%$; ** significant at $1 \%$. 


\section{Appendix B. Proof: The Sum of $m$ Half Normal Random Variables is Half Normal}

This proof uses this widely-used transformation theorem:

Theorem 1: Let $X$ be a continuous random variable with $\operatorname{pdf} f(x)$, and let $Y=u(X)$ define a oneto-one transformation between the values of $\mathrm{X}$ and $\mathrm{Y}$. Then the pdf of $\mathrm{Y}$, say $\mathrm{g}(\mathrm{y})$, is

$g(y)=f\left(u^{-1}(y)\right)|J|$

where $\mathrm{x}=\mathrm{u}^{-1}(\mathrm{y})$ is the inverse function of $\mathrm{y}=\mathrm{u}(\mathrm{x})$, and $J=\partial \mathrm{u}^{-1}(y) / \partial y$ denotes the Jacobian of the transformation. Note that $\mathrm{u}^{-1}$ is assumed to be differentiable.

Proof: For a detailed proof see Theorem 7.3 in Walpole et al. (2011).

Theorem 2: The sum of $m$ independently and identically distributed (i.i.d.) half normal random variables is half normal. Let $\mathrm{X} \sim$ i.i.d. half normal with parameter $\sigma$. Then, $\mathrm{X}$ has pdf

$f(x)=\frac{2 \sigma \mathrm{e}^{-\frac{x^{2} \sigma^{2}}{\pi}}}{\pi} \quad 0 \leq x<\infty, \sigma>0$.

Let $Y=\sum_{m} X=m X \quad$ where $m$ is an integer and $1 \leq m<\infty$. Then, using Theorem 1 ,

$g(y)=f\left(u^{-1}(y)\right)|J|=\frac{2 \sigma e^{-\frac{y^{2} \sigma^{2}}{m^{2} \pi}}}{m \pi}$

This is the pdf of a half normal random variable with parameter $\frac{\sigma}{m}$.

\section{Remarks:}

You can understand the conclusion that $g(y)$ is the pdf of a half normal random variable with parameter $\frac{\sigma}{m}$ in several ways. To immediately see that (B.2) is the pdf of a half normal random variable with parameter $\frac{\sigma}{m}$, set $m$ equal to one in (B.2). 
Given that $g(y)=2 \sigma e^{-\frac{y^{2} \sigma^{2}}{m^{2} \pi}} / m \pi$, let $m=1$. Then

$g(y)=2 \sigma e^{-\frac{y^{2} \sigma^{2}}{\pi}} / \pi$

This is clearly the pdf (B.1) except for the obvious difference that (B.3) is a function of $y$ rather than a function of $x$. Of course, when $m=1, y$ equals $x$.

Alternatively, change (B.1) into the pdf for a half normal random variable with parameter $\sigma / \mathrm{m}$ and compare the result with (B.2).

Given that $f(x)=2 \sigma e^{-\frac{x^{2} \sigma^{2}}{\pi}} / \pi$, let $\sigma=\sigma / m$. Then

$$
f(x)=2 \sigma e^{-\frac{x^{2} \sigma^{2}}{m^{2} \pi}} / m \pi
$$

The pdf (B.4) is exactly the same as the pdf in (B.2) except for the obvious difference that (B.4) is a function of $\mathrm{x}$ rather than a function of $\mathrm{y}$. That is, both the pdf $f(x)$ and the pdf $g(y)$ are probability density functions for random variables having the half normal distribution.

\section{Appendix C. Derivation of the pdf function for the composite error term in equation (11)}

Equations (C.1) and (C.2) below represent the baseline model estimated in the paper

$$
\begin{aligned}
& \Delta \pi_{t}=\alpha(L) \Delta \pi_{t-1}+\delta(L) z_{t}+\beta(L)\left(u_{t}-u_{t}^{*}\right)+\varepsilon_{t} \\
& u_{t}^{*}=\rho u_{t-1}^{*}+\omega_{t} \\
& v_{t}=u_{t}-u_{t}^{*}
\end{aligned}
$$

Iterative substitution of equation (C.2) and (C.3) into (C.1) produces the following equation

$$
\Delta \pi_{t}=\alpha(L) \Delta \pi_{t-1}+\beta(0) u_{t}-\beta(0) \rho u_{t-1}+\gamma^{w} w_{t}+\sum_{n=1}^{k} \gamma_{n}^{v} v_{t-n}+\varepsilon_{t}
$$


Here we assume that the AR(1) process error term $\omega_{t}$ and the lags of $v_{t}$ are independently and half-normally distributed. For this to hold, we implicitly assume that the error term in the AR(1) process at time $t$ does not depend on the previous period's total unemployment rate. Given that the distribution of a linear combination of independent half-normal variables is also half-normal, we can then derive the $p d f$ of the sum of the half-normal error terms in equation (C.4) as

$$
f\left(\xi_{t}\right)=\frac{\sqrt{2}}{\sqrt{\pi} \sqrt{\sigma_{w}^{2}\left(\gamma^{w}\right)^{2}+\sigma_{v}^{2} \sum_{n=1}^{k}\left(\gamma_{n}^{v}\right)^{2}}} * \exp \left(\frac{-\xi_{t}^{2}}{2\left(\sigma_{w}^{2}\left(\gamma^{w}\right)^{2}+\sigma_{v}^{2} \sum_{n=1}^{k}\left(\gamma_{n}^{v}\right)^{2}\right)}\right)
$$

where $\xi_{t}=\gamma^{w} w_{t}+\sum_{n=1}^{k} \gamma_{n}^{v} v_{t-n}, \sigma_{w}^{2}$ and $\sigma_{v}^{2}$ are the half-normal variables' variance, $\exp ($.$) is the$ exponential function and $f\left(\xi_{t}\right)$ denotes the $p d f$ function.

Let $\chi_{t}=\xi_{t}+\varepsilon_{t}$ denote the composite error term in (C.4) and define $\sigma$ and $\lambda$ as

$$
\begin{aligned}
& \sigma^{2}=\left(\sigma_{w}^{2}\left(\gamma^{w}\right)^{2}+\sigma_{v}^{2} \sum_{n=1}^{k}\left(\gamma_{n}^{v}\right)^{2}\right), \\
& \lambda=\left(\sigma_{w}^{2}\left(\gamma^{w}\right)^{2}+\sigma_{v}^{2} \sum_{n=1}^{k}\left(\gamma_{n}^{v}\right)^{2}\right)^{0.5} / \sigma_{\varepsilon}^{2},
\end{aligned}
$$

then using the formulation in Aigner et al. (1976), the $p d f$ for the composite error term can be derived as,

$$
f\left(\chi_{t}\right)=\frac{2}{\sigma \sqrt{2 \pi}} \Phi\left(\frac{\chi_{t} \lambda}{\sigma}\right) \exp \left(\frac{-\chi_{t}^{2}}{2 \sigma^{2}}\right)
$$

where $\sigma_{\varepsilon}^{2}$ is the normal variable's variance and $\Phi(\cdot)$ is the standard normal CDF. 
Figure 1. Total unemployment and our measure of structural unemployment

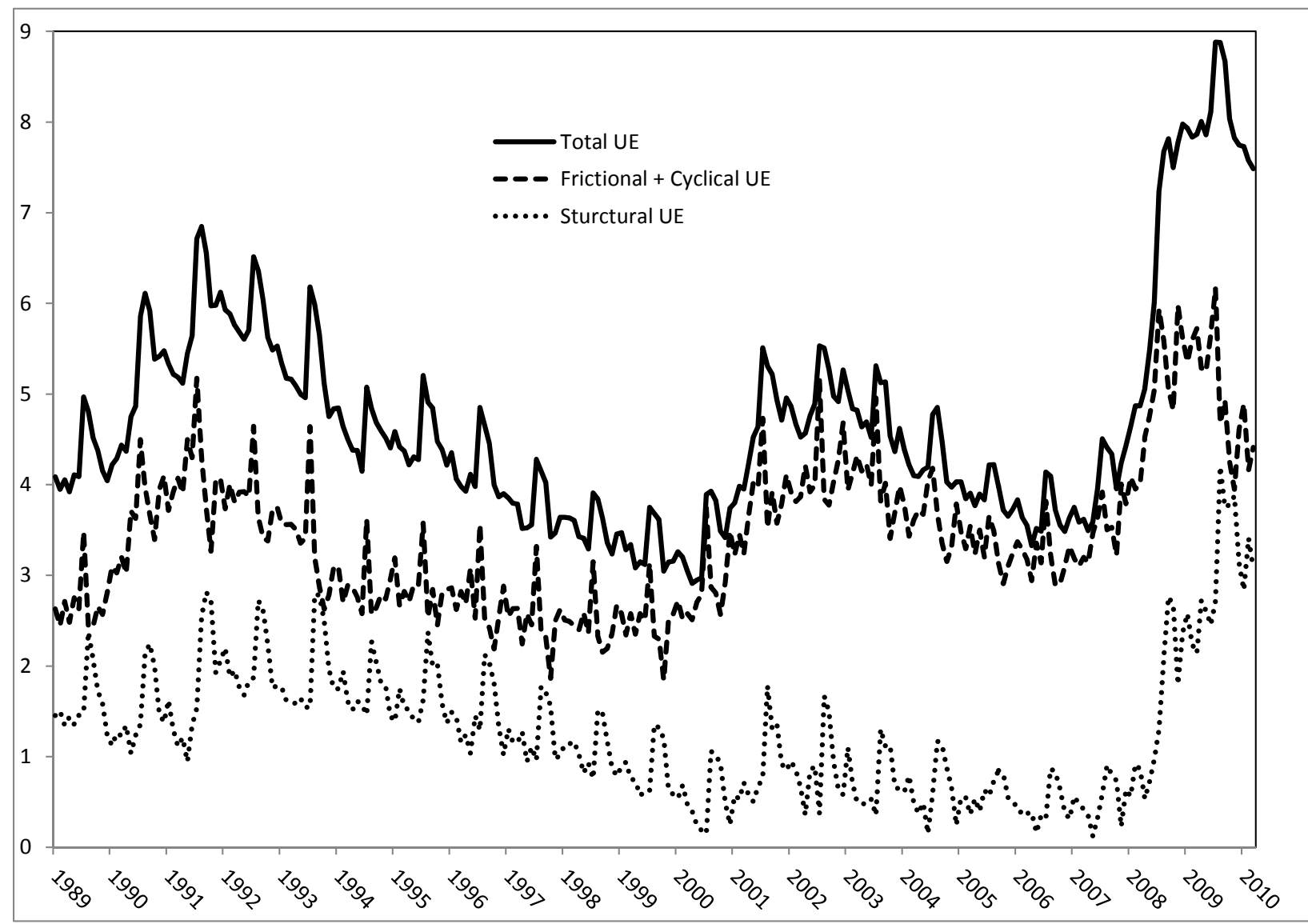

Note: The unemployment measures are not seasonally adjusted. Energy and import prices are used as the supply shock variables in estimating the structural unemployment rate. 
Figure 2. Structural Unemployment, 1960-2010

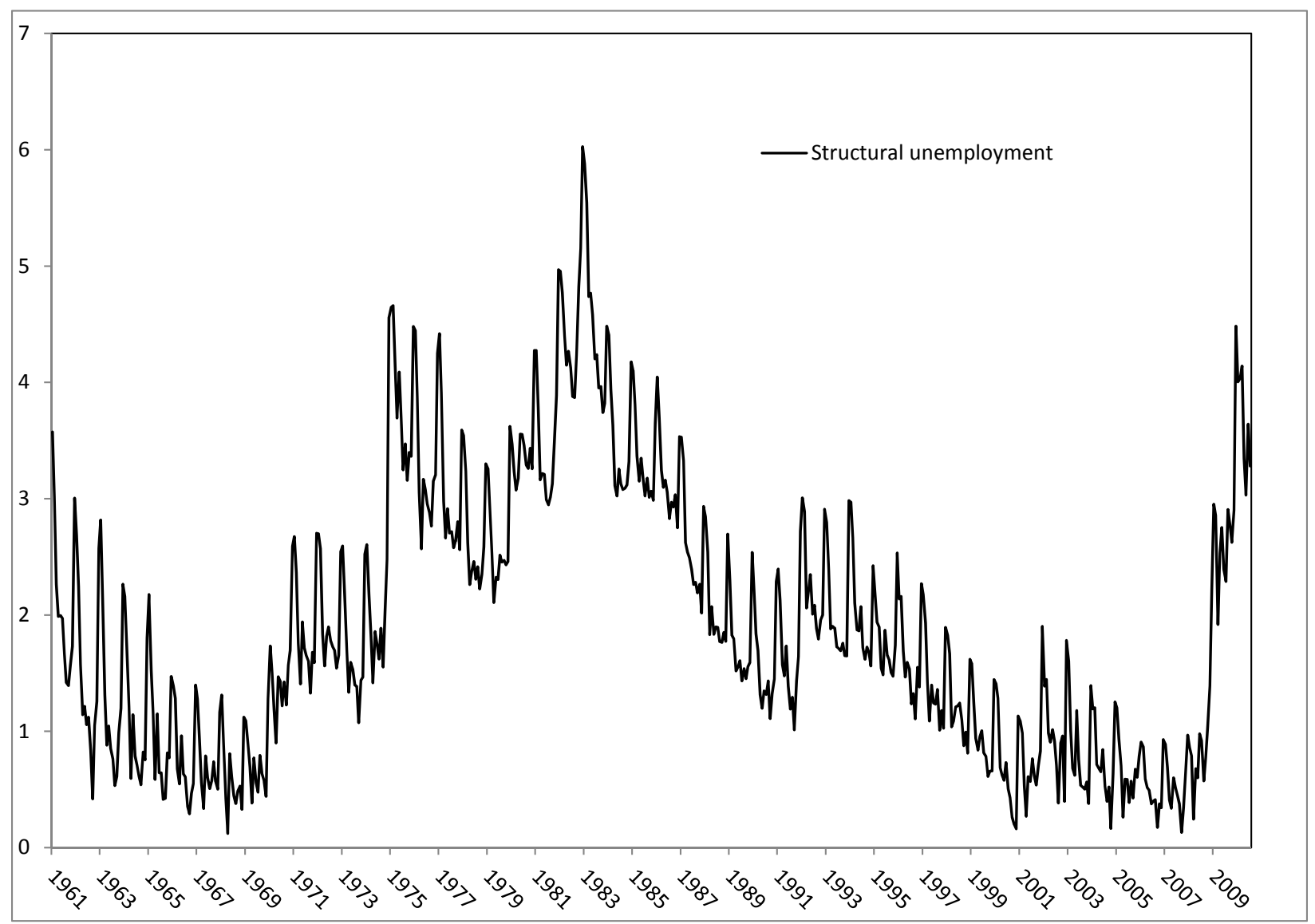

Note: Energy prices are used as the supply shock variable in estimating the structural unemployment rate. 
Table 1. Comparing our measure of structural unemployment with other measures

\begin{tabular}{|c|c|c|c|c|c|c|}
\hline & 1960s & 1970s & $1980 \mathrm{~s}$ & 1990s & 2000-2007Q2 & 2007Q3-2010Q3 \\
\hline$u^{* a}$ & 1.10 & 2.42 & 3.25 & 1.67 & 0.74 & 1.90 \\
\hline $\mathrm{CBO}$ & 5.65 & 6.13 & 6.04 & 5.39 & 5.00 & 5.12 \\
\hline & \multicolumn{2}{|c|}{ NAIRU Estimate } & & $u^{*}$ & & \\
\hline Rissman (1986) & \multicolumn{2}{|c|}{ 3.48\% (1966), 7.01\% (1981) } & & \multicolumn{2}{|c|}{ 0.79\% (1966), 3.40\% (1981) } & \\
\hline Staiger et al. (1997) & \multicolumn{3}{|c|}{ between $5.1 \%$ and $7.7 \% ; 6.5 \%$ (1990) } & $1.58 \%(1990)$ & & \\
\hline Turner at al. (2001) & $\begin{array}{l}6.1 \%(1980) \\
5.6 \%(1985) \\
5.4 \%(1990) \\
5.3 \%(1995) \\
5.2 \%(1999)\end{array}$ & & & $\begin{array}{l}3.30 \%(1980) \\
3.39 \%(1985) \\
1.58 \%(1990) \\
1.76 \%(1995) \\
0.99 \%(1999)\end{array}$ & & \\
\hline \multirow[t]{4}{*}{ Grant (2002) } & \multicolumn{2}{|c|}{$5.2 \%$ to $5.8 \%(1960 \mathrm{~s})$} & & $1.10 \%(1960 s)$ & & \\
\hline & \multicolumn{2}{|c|}{$5.0 \%$ to $5.2 \%(1970 \mathrm{~s})$} & & $2.42 \%(1970 \mathrm{~s})$ & & \\
\hline & \multicolumn{2}{|c|}{$5.9 \%$ to $6.2 \%(1980 \mathrm{~s})$} & & $3.24 \%$ (1980s) & & \\
\hline & \multicolumn{2}{|c|}{$6.1 \%$ to $6.3 \%(1990 \mathrm{~s})$} & & $1.67 \%$ (1990s) & & \\
\hline Arnold (2007) & \multicolumn{2}{|c|}{$5.3-5.5 \%(2007)$} & & $0.50 \%(2007)$ & & \\
\hline Daly et al. (2011) & $6.25 \%(2010)$ & & & $3.65 \%(2010)$ & & \\
\hline
\end{tabular}

Note: The structural unemployment variable that is used to compute the average $u^{*}$ values in the table are obtained from equation (12). 
Table 2. Demographic evidence

\begin{tabular}{|c|c|c|c|c|c|c|c|c|c|}
\hline & & $1960 \mathrm{~s}$ & $1970 s$ & $1980 \mathrm{~s}$ & $1990 \mathrm{~s}$ & 2000-2007Q2 & 2007Q3-2010 & Mean & Corr(u*,LFPR) \\
\hline \multirow[t]{2}{*}{ male } & $u^{*}$ & 1.5 & 3.0 & 4.7 & 2.9 & 1.7 & 3.8 & 2.9 & -0.36 \\
\hline & LFPR & 81.2 & 78.4 & 76.5 & 75.3 & 73.8 & 71.8 & 76.2 & \\
\hline \multirow[t]{2}{*}{ female } & $u^{*}$ & 2.8 & 4.4 & 4.4 & 2.4 & 1.3 & 2.1 & 2.9 & -0.46 \\
\hline & LFPR & 39.6 & 46.4 & 54.2 & 58.7 & 59.5 & 58.9 & 52.9 & \\
\hline \multirow[t]{2}{*}{ white } & $u^{*}$ & 1.5 & 3.1 & 3.8 & 2.1 & 1.0 & 2.5 & 2.3 & -0.01 \\
\hline & LFPR & 58.8 & 61.6 & 65.1 & 67.1 & 66.7 & 65.5 & 64.1 & \\
\hline \multirow[t]{2}{*}{ nonwhite } & $u^{*}$ & 6.3 & 8.6 & 11.2 & 7.0 & 4.7 & 6.3 & 7.3 & -0.59 \\
\hline & LFPR & 63.1 & 60.8 & 63.0 & 64.6 & 65.2 & 63.9 & 63.4 & \\
\hline \multicolumn{10}{|l|}{ Ages } \\
\hline \multirow[t]{2}{*}{$16-19$} & $u^{*}$ & 11.5 & 14.1 & 15.9 & 13.8 & 12.1 & 16.8 & 14.0 & -0.17 \\
\hline & LFPR & 47.0 & 54.0 & 54.9 & 52.3 & 46.1 & 37.2 & 48.6 & \\
\hline \multirow[t]{2}{*}{$20-24$} & $u^{*}$ & 4.8 & 7.7 & 9.0 & 6.6 & 5.5 & 8.4 & 7.0 & 0.54 \\
\hline & LFPR & 66.3 & 73.4 & 78.0 & 77.2 & 75.8 & 72.7 & 73.9 & \\
\hline \multirow[t]{2}{*}{$25-34$} & $u^{*}$ & 1.4 & 3.0 & 4.6 & 2.7 & 1.6 & 3.4 & 2.8 & 0.45 \\
\hline & LFPR & 66.7 & 74.1 & 82.0 & 83.8 & 83.4 & 82.5 & 78.8 & \\
\hline \multirow[t]{2}{*}{$35-44$} & $u^{*}$ & 0.6 & 1.4 & 2.6 & 1.4 & 0.5 & 1.8 & 1.4 & 0.38 \\
\hline & LFPR & 70.7 & 75.4 & 82.7 & 84.9 & 84.1 & 83.5 & 80.2 & \\
\hline \multirow[t]{2}{*}{$45-54$} & $u^{*}$ & 0.4 & 1.0 & 1.9 & 0.7 & 0.0 & 1.3 & 0.9 & -0.09 \\
\hline & LFPR & 72.6 & 73.0 & 77.3 & 81.8 & 82.1 & 81.4 & 78.0 & \\
\hline \multirow[t]{2}{*}{$55-64$} & $u^{*}$ & 0.6 & 0.9 & 1.6 & 0.7 & 0.0 & 0.9 & 0.8 & -0.57 \\
\hline & LFPR & 61.8 & 58.2 & 54.7 & 57.3 & 62.0 & 64.7 & 59.8 & \\
\hline \multirow[t]{2}{*}{$65+$} & $u^{*}$ & 1.9 & 2.7 & 1.5 & 1.5 & 0.9 & 2.6 & 1.8 & 0.46 \\
\hline & LFPR & 18.3 & 14.3 & 11.6 & 11.9 & 14.1 & 17.0 & 14.5 & \\
\hline \multicolumn{10}{|c|}{ Dynamic versus static structural unemployment } \\
\hline \multirow[t]{2}{*}{ gender } & dynamic & 1.9 & 3.6 & 4.6 & 2.7 & 1.5 & 3.0 & 2.9 & 0.31 \\
\hline & static & 3.2 & 3.4 & 3.3 & 2.9 & 2.5 & 1.5 & 2.8 & \\
\hline \multirow[t]{2}{*}{ race } & dynamic & 2.1 & 3.8 & 4.8 & 2.8 & 1.7 & 3.2 & 3.1 & 0.29 \\
\hline & static & 3.2 & 3.4 & 3.4 & 3.1 & 2.8 & 1.9 & 3.0 & \\
\hline \multirow[t]{2}{*}{ age } & dynamic & 2.1 & 3.8 & 4.8 & 2.8 & 1.7 & 3.2 & 3.1 & 0.39 \\
\hline & static & 3.3 & 3.9 & 3.6 & 2.8 & 2.2 & 1.1 & 2.8 & \\
\hline
\end{tabular}

Note: The table reports the average structural unemployment rates that are computed separately for each demographic group by estimating equation (11). The static measures displayed in the bottom panel are obtained by estimating equation (11) separately for each demographic group, assuming that the structural unemployment rate is constant. The time variation in these measures represents the changes in the participation rates of the demographic groups. 
Table 3. Regional structural unemployment and descriptive statistics

\begin{tabular}{|c|c|c|c|c|c|c|c|c|c|}
\hline & $\begin{array}{c}\text { New } \\
\text { England }\end{array}$ & $\begin{array}{c}\text { Mid } \\
\text { Atlantic }\end{array}$ & $\begin{array}{c}\text { East North } \\
\text { Central }\end{array}$ & $\begin{array}{c}\text { West North } \\
\text { Central }\end{array}$ & $\begin{array}{c}\text { South } \\
\text { Atlantic }\end{array}$ & $\begin{array}{c}\text { East South } \\
\text { Central }\end{array}$ & $\begin{array}{c}\text { West South } \\
\text { Central }\end{array}$ & Mountain & Pacific \\
\hline$u^{*}$ - mean & 2.0 & 3.2 & 3.0 & 1.5 & 2.5 & 3.2 & 2.8 & 2.4 & 3.7 \\
\hline $\mathrm{u}^{*}-1970 s$ & 4.2 & 5.6 & 3.4 & 1.8 & 3.8 & 3.3 & 2.8 & 3.4 & 5.0 \\
\hline $\mathrm{u}^{*}-1980 \mathrm{~s}$ & 2.1 & 4.1 & 5.2 & 2.9 & 3.5 & 5.6 & 4.5 & 3.8 & 4.4 \\
\hline $\mathrm{u}^{*}-1990 \mathrm{~s}$ & 2.2 & 3.1 & 1.8 & 0.8 & 2.0 & 2.2 & 2.7 & 1.8 & 3.6 \\
\hline $\mathrm{u}^{*}$ - 2000-2007Q3 & 0.6 & 1.4 & 1.3 & 0.4 & 0.9 & 1.3 & 1.5 & 0.9 & 2.0 \\
\hline $\mathrm{u}^{*}$ - 2007Q4-2010 & 1.9 & 2.3 & 3.1 & 1.1 & 2.7 & 2.9 & 1.4 & 2.0 & 3.9 \\
\hline \% primary sector & 0.7 & 0.9 & 1.9 & 5.4 & 2.1 & 3.0 & 12.3 & 7.4 & 3.6 \\
\hline \% secondary sector & 21.8 & 18.9 & 28.5 & 22.1 & 19.9 & 28.2 & 20.3 & 16.3 & 18.8 \\
\hline \% tertiary sector & 77.5 & 80.3 & 69.6 & 72.5 & 78.0 & 68.8 & 67.4 & 76.3 & 77.6 \\
\hline \% 15-64 & 66.1 & 65.8 & 65.3 & 64.0 & 65.9 & 65.1 & 65.0 & 65.0 & 66.7 \\
\hline \% female & 51.4 & 52.0 & 51.0 & 50.7 & 50.1 & 50.6 & 49.6 & 48.5 & 49.0 \\
\hline \% white & 91.0 & 80.2 & 85.0 & 91.6 & 75.7 & 78.8 & 75.9 & 85.6 & 73.2 \\
\hline LFPR & 60.8 & 56.7 & 58.4 & 61.2 & 58.2 & 55.1 & 57.2 & 59.2 & 59.6 \\
\hline LFPR women & 51.7 & 51.7 & 54.5 & 54.5 & 52.3 & 52.3 & 52.3 & 54.1 & 54.1 \\
\hline
\end{tabular}

Note: Primary sector includes agriculture and mining, secondary sector includes manufacturing and construction and the tertiary sector includes services.

Table 4. Regional determinants of structural unemployment

\begin{tabular}{|c|c|c|c|c|c|c|}
\hline \multirow[b]{2}{*}{ Structural unemployment lags } & \multicolumn{3}{|c|}{ 3-year averages } & \multicolumn{3}{|c|}{ 5-year averages } \\
\hline & 0.007 & 0.010 & 0.012 & 0.006 & 0.007 & 0.010 \\
\hline & $(6.694) * * *$ & $(97.517)^{* * *}$ & $(188.427)^{* * *}$ & $(3.746) * * *$ & $(6.961)^{* *}$ & $(31.463)^{* * *}$ \\
\hline \multirow[t]{2}{*}{$\%$ primary } & -0.143 & -0.311 & -0.573 & -0.072 & -0.174 & -0.635 \\
\hline & $(12.345)^{* * *}$ & $(16.148)^{* * *}$ & $(37.664)^{* * *}$ & $(91.626)^{* * *}$ & $(37.875) * * *$ & $(103.893)^{* * *}$ \\
\hline \multirow[t]{2}{*}{ \% secondary } & 0.062 & 0.157 & & 0.067 & 0.214 & \\
\hline & $(33.188)^{* * *}$ & $(9.262)^{* *}$ & & $(23.908)^{* * *}$ & $(10.88)^{* *}$ & \\
\hline \multirow[t]{2}{*}{$\%$ tertiary } & & & -0.273 & & & -0.388 \\
\hline & & & $(15.158)^{* * *}$ & & & $(24.604)^{* * *}$ \\
\hline \multirow[t]{2}{*}{$\% 15-64$} & & -0.149 & 0.091 & & -0.149 & 0.19 \\
\hline & & $(0.089)^{*}$ & $(0.114)$ & & $(0.098)$ & $(0.183)$ \\
\hline \multirow[t]{2}{*}{$\%$ female } & & 0.095 & 0.149 & & 0.059 & 0.161 \\
\hline & & $(0.035)^{* * *}$ & $(0.04)^{* * *}$ & & $(0.049)$ & $(0.041)^{* * *}$ \\
\hline \multirow[t]{2}{*}{$\%$ white } & & -0.046 & -0.008 & & -0.045 & -0.014 \\
\hline & & $(0.027)^{* *}$ & $(0.019)$ & & $(0.033)$ & $(0.019)$ \\
\hline \multirow[t]{2}{*}{ LFPR } & & -0.168 & -0.205 & & -0.212 & -0.255 \\
\hline & & $(0.093)^{* *}$ & $(0.103)^{* *}$ & & $(0.1)^{* *}$ & $(0.104)^{* *}$ \\
\hline \multirow[t]{2}{*}{ LFPR-women } & & 0.295 & 0.388 & & 0.362 & 0.485 \\
\hline & & $(0.175)^{* *}$ & $(0.184)^{* *}$ & & $(0.175)^{* *}$ & $(0.159)^{* * *}$ \\
\hline Number of observations & 72 & 72 & 72 & 42 & 42 & 42 \\
\hline Sargan test & 0.604 & 0.907 & 0.967 & 0.973 & 0.781 & 0.956 \\
\hline Arellano-Bond test for AR(2) & 0.806 & 0.305 & 0.199 & 0.639 & 0.778 & 0.571 \\
\hline
\end{tabular}

Note: The results are obtained from the estimation of equation (13). The F-statistics in parentheses for the first four variables test for joint significance. ${ }^{*}$ significant at $10 \%$; ${ }^{* *}$ significant at $5 \%$; ${ }^{* *}$ significant at $1 \%$. 